\title{
Exploring Our Options: Modern Publishing Alternatives for our Computer Programming Textbook
}

\author{
Ronald Erdei and Kyle Lutes \\ Department of Computer and Information Technology, \\ Purdue University, USA
}

\author{
erdeira@purdue.edu kdlutes@purdue.edu
}

\begin{abstract}
The authors of this paper are also the authors of an introductory computer programming textbook used in several college courses. Due to the rapidly changing content, the textbook requires frequent revisions causing the shelf-life of each specific version of the textbook to be relatively short, sometimes being no longer than a single semester. In addition, the time required to actually print a new version of the textbook and make it available to students was too long considering the time-sensitivity of the content and frequency of revisions. For these reasons, traditional publishing of this textbook was an unsatisfactory option.

In this paper, we describe our exploration of alternatives to traditional textbook publication in hopes of finding an easy, uncomplicated, and rapid means of textbook publication. Our findings on ease of content creation/revision, time-to-market, monetization, and digital rights management are presented in this paper. Finally, we present our criteria for a publishing option we think is needed for authors who publish textbooks on similar rapidly changing domain topics.
\end{abstract}

Keywords. textbook, alternative publishing, self-publishing, University Press, Lulu, Flat World, Knowledge App Store

\section{Introduction}

Modern academics seeking to publish textbooks via the traditional commercial publication process face many challenges unknown only 30 years ago. Some of these challenges stem from technological advances, such as the used textbook market made possible by the combination of networked inventory systems and efficient freight transportation methods. Other challenges stem from current business practices of commercial publishers, such as the expectation that expensive and often unused ancillary products be included in academic textbooks. From an author's perspective, it is much more difficult to have a textbook commercially published via the traditional

Material published as part of this publication, either on-line or in print, is copyrighted by the Informing Science Institute. Permission to make digital or paper copy of part or all of these works for personal or classroom use is granted without fee provided that the copies are not made or distributed for profit or commercial advantage AND that copies 1) bear this notice in full and 2) give the full citation on the first page. It is permissible to abstract these works so long as credit is given. To copy in all other cases or to republish or to post on a server or to redistribute to lists requires specific permission and payment of a fee. Contact Publisher@InformingScience.org to request redistribution permission. process now than ever before. However, the effects of the last 30 years have not been entirely negative. New and innovative tools have been made available to modern textbook authors, providing them with viable alternatives to the traditional commercial publication process. For example, commercial publishers that use non-traditional business models, such as University Presses, are well positioned to serve markets found at the 
upper end of the academic curriculum - markets often neglected by traditional commercial publishers due to their lack of profitability. Similarly, a great many resources are available - some fee-bearing, some free of charge - to textbook authors seeking to forgo commercial publication entirely and instead self-publish their work.

The textbook we have authored focuses on teaching introductory-level application development concepts and practices to college undergraduates. Though the concepts are often long lived, the specific details of the content area are rapidly changing necessitating frequent revisions to the text. These revisions are necessary not only to keep the content current, but also to prevent the presentation of deprecated information, syntax, and techniques. Thus, the ability to quickly revise content and publish updated versions of the textbook is highly desirable. Time-to-market (i.e. the time required to print, distribute, stock, and get the textbooks into the hand of students) is also critical to keeping textbook content valid when addressing a rapidly changing subject domain.

In the experience of the authors, the traditional publishing life cycle is far too long for the needs of computing-related textbooks. In our case, the traditional publishing life cycle resulted in new versions of our textbook being made available to students at most every three years. Exasperating the issue of timeliness, the authors have experienced delays in the deployment of new editions of the textbook as the publisher sought to sell inventory and surplus prior to printing a new edition. Finally, the inclusion of ancillaries - such as extensive assessment banks, costly web-based forums, and little used collaboration tools - is a modern standard to traditionally published textbooks. Yet, in our experience these ancillaries provide little benefit to the target audience relative to the large investment of time and finance their development, inclusion, and support require.

This paper begins by identifying modern issues with, in general, problems with traditional textbook publishing.

\section{Problems with Traditional Textbook Publishing}

Problems with the traditional textbook publication process are well documented. Unnecessary and often unused ancillary resources - typified by elaborate assessment banks, online forums, and web-based collaboration tools - target textbook adoption committees instead of the needs of the student. The cost of developing and supporting these ancillaries is high, and recoverable by the publisher only through textbook sales. Thus ancillary inclusion causes a significant increase in the price of a textbook, and is unfortunately considered to be a necessity to textbook adoption (United States Government Accountability Office, 2005, p.11).

A parallel problem, the growth of the used textbook market, has caused a further increase in textbook prices as publisher revenue generation through sale of new textbooks has been truncated (Thompson, 2005, p. 213). In tandem, these two issues have led to the price of textbooks approximately tripling over the last two decades, ultimately resulting in consumer dissatisfaction so intense there has been congressional inquiry into the textbook publication process" (Hearing on: Are College Textbooks Priced Fairly, 2004).

An additional result of ancillary inclusion and truncated revenue streams is that traditional publishers are forced to focus only upon the largest markets if they hope to recover their expenses and actually generate profit. This has led publishers to marginalize material supporting the upper end of the curriculum as these smaller markets are seen as unprofitable (Thompson, 2005, p. 222).

Finally, the traditional publication process can be cumbersome for authors forced to learn and apply publisher-specific typesetting requirements into their textbook content. This is especially true for those authors integrating complex graphics and inline computer source code into their books. 


\section{Alternatives to Traditional Textbook Publishing}

\section{University Presses}

Many colleges and universities host their own publication divisions, known as university presses. Unlike their commercial counterparts, university presses are not-for-profit publishers with a focus upon publications of a scholarly nature - publications which are typically ignored by commercial publishers due to the small market appeal they possess.

The Association of American University Presses, a world-wide organization containing over 130 members, describes the role of the university press as follows:

University presses are publishers. At the most basic level that means they perform the same tasks as any other publisher - university presses acquire, develop, design, produce, market and sell books and journals, just like Random House or Condé Nast. But while commercial publishers focus on making money by publishing for popular audiences, the university press's mission is to publish work of scholarly, intellectual, or creative merit, often for a small audience of specialists.

Many of the books university presses publish, then, are meant primarily for scholars or other people interested in certain concentrated fields of research. Thousands of these books (generally termed monographs) have been published, on topics ranging from the meaning of gambling in nineteenth-century America to the changing nature of Balinese gamelan music. Monographs are generally sold in hardcover editions to libraries, and increasingly in paperback editions so that they may be used as supplemental reading in college courses (AAUP - About Ups, n.d.).

Due to the hyper-specialized nature of many research niches - niches explored at the upper end of the academic curriculum - textbooks upon these topics are often ignored by commercial publishers due to their small market size. However, according to Charles Watkinson, Director of the Purdue University Press, the nature of university presses make them ideal publishers of these works. University presses thus provide a much needed means for publication of textbooks that support the upper end of the academic curriculum (i.e., upper-level undergraduate, graduate, and postgraduate courses) (Watkinson, C., personal communication, April 18, 2011).

It should also be noted that university presses couple far fewer ancillaries with their publications. This allows university presses to forgo one extremely large source of publication overhead, ultimately allowing them to provide textbooks at a much lower cost to consumers (i.e., students) than would be possible for their commercial counterparts (Watkinson, C., personal communication, April 18, 2011).

\section{Self-Publication}

Forgoing the use of a commercial publisher or university press, self-publication of textbooks is a viable alternative for many. According to Thompson (2005, pp. 24-25), publishers perform six value-adding functions. To those wishing to self-publish, five of these functions remain relevant. They are:

- Financial investment: cover the cost of expenses, advance funds to authors while they work, etc. acquisition and annual maintenance of an International Standard Book Number (ISBN)

- Content development: direction and guidance, graphics development, copyright research, etc.

- Quality control: copy-editing, validation of content by peers, etc.

- Management and coordination: managing freelance services such as printers and freelance specialists such as graphic designers, etc. 
- Sales and marketing: establishing a distribution system, introducing your product to potential customers, etc.

Self-publication of a textbook is no small task. And fulfilling the functions typically performed by the publisher requires a significant investment of resources. Chief amongst which is time: time to copy-edit, time to perform quality control, time to establish a means of printing, time to establish a means of distribution, and time to perform the potentially dozens of other functions normally performed by the publisher. In addition to time, many of these functions possess upfront costs, thus sufficient finances are also required of those seeking to self-publish a textbook.

However, many modern resources are available to assist those seeking to self-publish their work. Especially useful are:

- information technologies: personal computers, digital cameras, scanners, etc.

- computer software: word processing programs, graphics design and editing programs, etc.

- service providers: printing services, copy-editing services, etc.

- organizations and associations: Text and Academic Authors Association, Society of Academic Authors

An Editorial Board member of the Purdue University Press and author of over a dozen books himself points out that self-published textbook rarely undergo the rigorous quality assurance measures to which commercial publishers and university presses subject their products. Because of this, the validity of self-published content is in greater doubt than had it been published commercially or through a university press. For similar reasons, the credibility of self-published textbooks is often less than traditionally published counterparts (Mohler, J., personal communication, April 20, 2011).

\section{Publication as a Service}

Several companies currently provide services typically performed by commercial publishers to those seeking to self-publish. These services are available on-demand and for-a-fee, and companies providing them are sometimes referred to as vanity presses, subsidy presses, or selfpublication companies. However, we will refer to these companies as 'publication as a service' providers.

Started in 2002, Lulu is perhaps the best known example of a publication as a service provider.

At Lulu ... authors can create everything from hardcover books to eBooks, photo books to calendars ... If authors need any help along the way - with cover design, editing, formatting, marketing or the publishing process in general - our services team can provide expert assistance through a la carte offerings and bundled packages (Lulu Corporate Profile, n.d.).

Amazon-owned CreateSpace is another prominent publication as a service provider.

With CreateSpace you can easily access tools, quality printing, booksellers, eBook distribution, and marketing strategies so that you can generate more opportunities than you imagined - all while building your following of readers (CreateSpace: Self-Publishing and Free Distribution for Books, CD, DVD., n.d.).

Jane Friedman at Dog Ear Publishing, a publication as a service provider, writes that "for the typical self-published author ... a significant amount of frustration, time, and money can be saved by using self-publishing companies" (Dog Ear - Self-Publishing Companies, n.d.). However, she also points out that: 
Self-publishing companies are only the same in the fact that we all use almost the exact same technologies to print books. Each company has a unique approach to the market, and a distinct personality (Dog Ear - Self-Publishing Companies, n.d.).

With this in mind, those contemplating use of a publication as a service provider during selfpublication should thoroughly research available providers to identify best-fit.

\section{Open Education Resources}

Open-source education resources, also known as open education resources or OERs, are resources typically available for non-commercial, educational purposes at no cost. These resources are usually licensed under Creative Commons copyright licenses which provide "alternatives to the "all rights reserved' traditional copyright” (Creative Commons, n.d.). Specifically:

All Creative Commons licenses share many important features . Every license helps creators ... retain copyright while allowing others to copy, distribute, and make some uses of their work - at least non-commercially. Every Creative Commons license also ensures licensors get the credit for their work they deserve. Every Creative Commons license works around the world and lasts as long as applicable copyright lasts (because they are built on copyright). These common features serve as the baseline, on top of which licensors can choose to grant additional permissions when deciding how they want their work to be used (Creative Commons - About The Licenses, n.d.).

In the latter 1990s, several prominent academic institutions began investigating the feasibility of sharing their educational resources - free of charge - with fellow educators, students and members of the community at large. Carnegie Mellon's thriving OpenLearningInitiative (OLI), and Massachusetts Institute of Technology's OpenCourseWare (OCW) are two such initiatives.

In 1999, MIT Faculty considered how to use the Internet in pursuit of MIT's mission - to advance knowledge and educate students - and in 2000 proposed OCW. MIT published the first proof-of-concept site in 2002, containing 50 courses. By November 2007, MIT completed the initial publication of virtually the entire curriculum, over 1,800 courses in 33 academic disciplines. Going forward, the OCW team is updating existing courses and adding new content and services to the site (MIT OpenCourseWare - About OCW, n.d.).

Initiatives such as these led to the OpenCourseWare Consortium, a "collaboration of higher education institutions and associated organizations from around the world creating a broad and deep body of open educational content" (OCW Consortium, n.d.). The consortium has over 130 members, including such prestigious academic institutes as Massachusetts Institute of Technology, John Hopkins Bloomberg School of Public Health, and University of California - Berkeley (OCW Consortium - Members, n.d.). Individual members of the OpenCourseWare Consortium, as well as the consortium itself, provide many resources to facilitate development and selfpublication of OERs, including textbooks.

\section{Flat World Knowledge}

Flat World Knowledge is an innovative, online publishing company possessing a business model differing significantly from traditional commercial publishers, university presses, and publication as a service providers. The three most significant differences are:

- textbooks are licensed under a Creative Commons license allowing individuals (i.e., course instructors) to alter content

- content alterations can be retained, and the textbooks made available to purchasers in either the original or altered form

- full versions of textbooks may be read online at no cost 
The following example was provided by Flat World Knowledge:

Suppose an instructor loves your book, except for one thing - they use a different approach to your coverage of Chapter 5. They go to the Web-hosted version, and create a COPY of your original version. They can now do whatever they like to their copy, and it will "track changes" so that you can see the difference between their work and your original work. They click "publish," and the new book (with the new Chapter 5) goes live! They get a unique product identifier to give to their class, so that students can access the "new" version (Flat World Knowledge - Authors, n.d.).

Similar to the model of traditional commercial publishers, revenue is primarily generated by textbook sales to students. Textbooks are available to students in various formats, and currently include:

- Hardcopy: printed black \& white or color hardcopy with a softcover

- PDF: downloadable adobe portable document format (PDF) which can be read offline or printed out on a personal printer

- Audiobook: MPEG Audio Layer III (MP3) format for use in mp3 players

- eBook: iPad, Kindle, or Sony Reader format

- Online

Price reflects textbook size and varies by selected format, however online access is always free (Flat World Students - Books, n.d.). Revenue is also generated by sale of study aids (e.g., flashcards, practice quizzes, study guides, etc.) to students (Flat World Knowledge - Authors, n.d .).

\section{Fitness of Specific Alternatives to our Needs}

The following criteria were used in assessing each of the alternative publication methods for fitness to our needs.

- Retention of copyright ownership

- Ease of content creation and revision

- Time-to-market

- Out of pocket costs

- Financial benefit

- Distribution formats

- Marketing and advertising

- Points of sale (i.e., Where can students purchased it)

- Content Protection (i.e., Piracy Prevention)

- Credibility associated with publication method

No system of weighting was established for the various criteria. However, some criteria were clearly more important to us, such as the retention of copyright ownership.

\section{Assessment of Specific Alternative Publication Methods}

\section{University presses}

Publication of our textbook via a University Press provides two significant advantages over traditional publication. First, it would mitigate the pressure to develop and support unnecessary textbook ancillaries. Second, it would alleviate the pressure to market the textbook to the broadest possible audience, instead allowing us to remain focused upon the changing content area and specific needs of the target audience. Financial compensation would take the form of royalties based 
upon textbook sales, with royalty rates being negotiated prior to publication. Copyright ownership of textbook content is retained by the authors, and no out-of-pocket expenses are required to publish.

However, the editing practices and publication methodologies used by University Presses are similar to traditional publication practices and methodology. Thus authorship would require usage of special markup, which would in turn increase the complexity of the content creation and revision processes. Relatedly, the speeds of content creation and revision, speed of textbook publication, and time-to-market would all be inhibited by the practices and methodologies employed by University Presses.

\section{Publication as a service: Lulu}

Lulu is both well established and well known amongst publication-as-service providers, and it is for this reason that we explored self-publication of our textbook using Lulu provided services. In assessing these services we found that a great many advantages could be had by self-publishing as compared to the traditional publication process. One of the primary advantages possessed by Lulu is that content can be created in a standard word processing program without need for special markup, thus easing the burden of authorship. Various services are available to assist with distribution, and to a lesser extent marketing. Several distribution formats are available, including both print text and electronic. Though some services provided by Lulu allow print copies of textbooks to be made available at "brick and mortar" retailers, point of sale is typically online and includes such retailers as Amazon and the iBookstore.

However, no matter the distribution format or channel, when using Lulu services you retain full copyright ownership. Financial compensation is straight forward: the author sets the final price of the book, and retains $80 \%$ of the profit on all textbook sold (Lulu Corporate Profile, n.d.). Financial compensation can be set up either as royalties from Lulu, or as "other revenue". However, the cost of all Lulu provided services are paid out of pocket and "up front". In addition, Lulu printing and distribution services report a moderate time-to-market: 1 to 2 months (Lulu - How does the distribution process work?, n.d.).

\section{Open education resource}

Publication of our textbook via open education resources was quickly discounted as a viable alternative. One of the primary disadvantages in the use of open education resources is the requirement that publications use the Creative Commons copyright license, which the authors felt would not allow us to retain sufficient control of our intellectual property. An additional disadvantage to the usage of open education resources is the prevention of financial compensation to selfpublishing authors for the investment of time, specialized knowledge, and out of pocket expenses in authoring the textbook.

\section{Flat world knowledge}

Publication of our textbook via Flat World Knowledge would provide several advantages over traditional publication methods. First and foremost, the printing services used by Flat World Knowledge are truly on-demand. So much so that students purchasing the textbook can choose not simply its format, but it's very binding style when requesting one be printed. In addition, students are always able to access the book, free of charge, via the Flat World Knowledge web site (they cannot, however, download it free of charge). Point of sale is online, and both print text and electronic formats are available. Delivery of hard copy textbooks, printed to the purchaser's specifications, occurs roughly a week after purchase. 
Unfortunately, publishing with Flat World Knowledge requires using a Creative Copyright license which the authors felt would not allow adequate control of intellectual property. A second disadvantage is that material published via Flat World Knowledge undergoes an editing process similar to that imposed by traditional publishers, thus hampering our ability to quickly and easily revise textbook content. Finally, it is unclear the extent to which authors are financially compensated for their intellectual property.

\section{Full self-publication}

Fully self-publishing our textbook would provide several advantages over traditional publication methods. First, we could edit content using word processing software of our choice without having to worry about printing or editorial markup. Second, we could release new versions of the textbook as often as content changes justified it. And third, we could limit inclusion of ancillaries to only those that were used, added actual educational benefit, and were cost efficient.

However, fully-self publishing the work would mean all authors would need to agree upon a standard means of editing the content, as well as putting in place safeguards to prevent catastrophic loss due to computer failure, accidents to authors, etc. Fortunately, all authors were proficient with Microsoft Word thus making the choice of editing software easy. In addition, as application developers, all authors were familiar with source code control software, which is used to prevent loss of computer source code, and also provides check-out/in and version control features.

A suitable means of printing the textbook, distributing the textbook, and selling the textbook would also have to be found if we were to fully self-publish the textbook. Various printing services were available both online and locally, but the best fit for our needs came from the University Printing services offered at our school. These services were already in place, and were familiar to both faculty and students as supplemental course materials (i.e., course packets, laboratory packets, etc.) were often provided by course instructors for printing, with subsequent purchase and pickup by students.

\section{Summary of Alternatives}

The fitness of each alternative in regards to our needs has been summarized in Table 1.

Content protection, especially in regards to piracy of content provided in electronic formats, is a significant concern of the authors. Because none of the publication alternatives investigated addressed content protection in any meaningful way, it was not included in the individual assessments above. However, it has been included in the table. 
Table 1: Assessment of Publication Alternatives by Specific Criteria

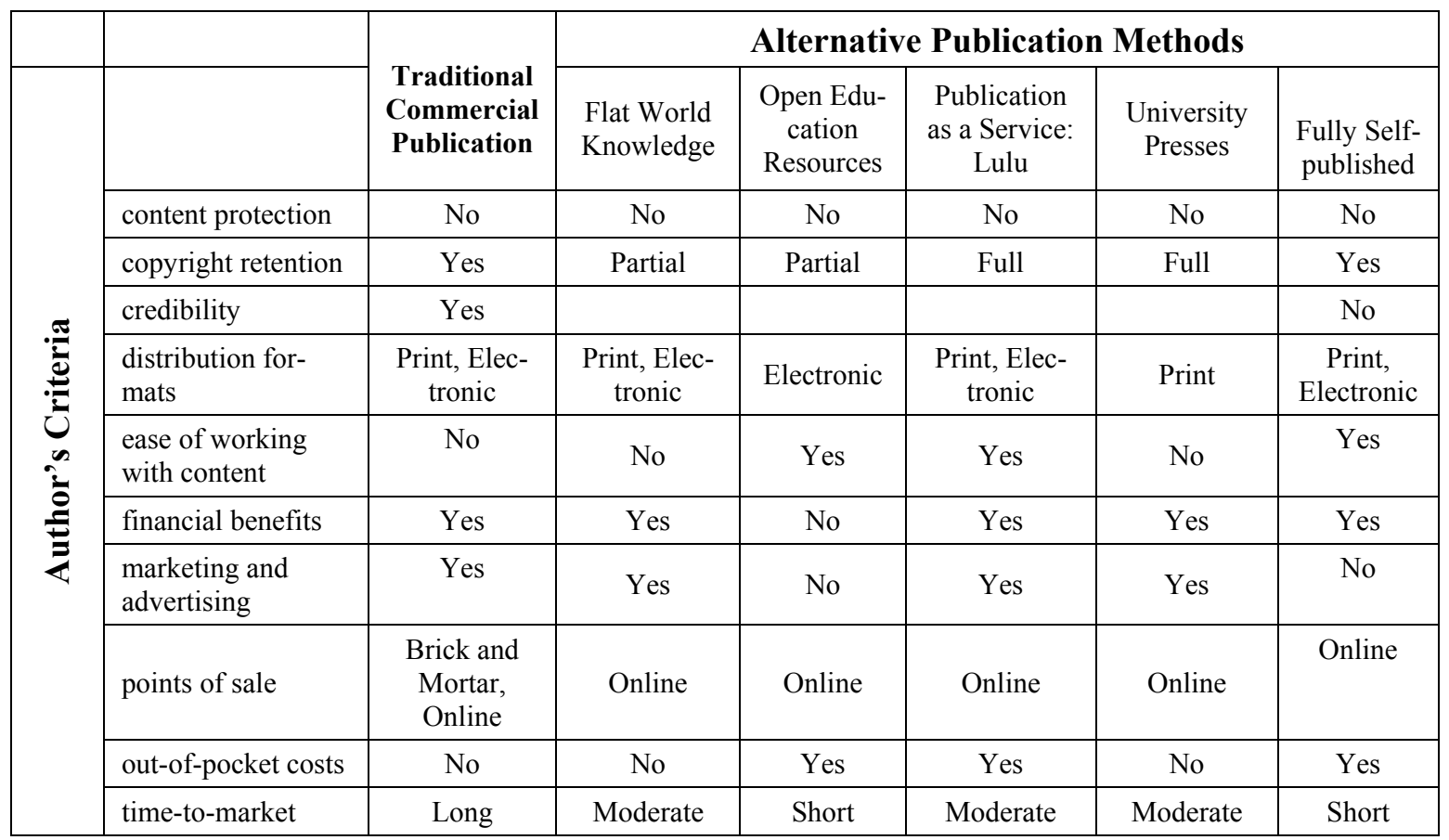

\section{Publication Expectations}

\section{Monetization}

We felt we should expand our investigation to also include financial benefit to the authors. Authors of traditionally published textbooks are financially compensated in the form of textbook royalties. Royalty rates are negotiated prior to publication of the textbook, but can vary widely between authors. Several authors were interviewed during the course of this investigation, with the lowest royalty rate being reported at $3 \%$ and the highest at $14 \%$. For purposes of example, we assume a middling royalty rate of $7 \%$ on a 400 page textbook, printed in color, with a cover price of $\$ 125$. As it is traditionally published, the textbook authors need not bother themselves with details (or costs) of printing, marketing, distributing, or actually selling the textbook. In this case, the textbook authors would receive $\$ 8,750$ in royalties for every 1000 textbooks sold.

In contrast, many of the alternative publications allow the author to stipulate a flat rate per textbook sold instead of a percentage of the cover price. This rate factors directly into the subsequently calculated cover price of the textbook. For purposes of example, we assume a flat rate of $\$ 10$ per textbook be paid to the authors and a printing cost of $\$ 40$ for a 400 page textbook printed in color. Factoring in a $20 \%$ charge by Lulu for their distribution and sales services, the textbook would have a $\$ 52.50$ cover price. The authors would receive $\$ 10,000$ in compensation for every 1000 textbooks sold. However, this allows only a minimum of distribution channels (i.e., the textbook may be purchased only online from the Lulu website) and completely ignores the costs monetary, skillset, and time - associated with editing of content and marketing of the textbook. Adding additional distribution channels, such as making the textbook available via Amazon.com, can significantly increase the costs, as can the incorporation of marketing. 


\section{An "App Store" for Textbooks?}

As software developers who have created applications for smartphones and other mobile devices, we are familiar with the Apple App Store and how it has changed the model for how software is created, marketed, sold, and updated. While Apple's App Store is not successful because it offers services never heard of before, what it has done is it combined all the services a software developer needs besides that of developing an application. Services provided by the Apple App Store include:

- Free developer tools

- Management of developer accounts

- A governing body to prevent poor quality or inappropriate titles from being made available

- Search and browse features to easily enable users to find titles

- A ratings system so users can indicate to others the overall quality and value of a title

- An easy to use payment system (i.e. iTunes) that allows users to purchase apps without having to enter credit card information for each purpose

- Digital Rights Management (DRM) to deter unauthorized copying of intellectual property

- Developer metrics in the form of number of installs and uninstalls

- A system to easily allow developers to provide updates to their apps and an easy way for users to know when an update is available

- Monetization options in the form of allowing the developer to set the prices for the app, in app advertising, and in app purchases

- Payments made to content creators

Apple provides all of these services with a simple profit sharing plan of $70 \%$ of the app price for the author, 30\% of the app price for Apple, and a $\$ 99$ per year developer fee. No lengthy contract negotiations are needed or allowed. By providing all services from a single vendor, Apple has allowed small software developer shops to compete with big software companies and greatly reduce an application's time to market for both the first addition, and any subsequent revisions and editions to a software title.

When we review the features provided by the Apple App Store, and compare those features to what we desire in a textbook publishing service, we find the Apple App Store model provides nearly all the features we desire. In fact, we believe that if a textbook publishing system existed emulated the Apple App Store model for computer software, and provided an additional feature of a user being able to order a printed copy instead of an electronic download, it would revolutionize the way college textbooks are created and consumed.

\section{Conclusions}

When we began this exploration into publication alternatives we were hoping to locate a means of publishing our textbook that met all of our requirements. Unfortunately, our exploration did not reveal any such alternative currently in existence. Several alternatives were located however, each possessing both strengths and weaknesses, thought as stated above, none sufficient for our needs. We propose a new or existing textbook publishing company take a cue from Apple and create an App Store-like service for textbooks so that authors such as ourselves who wish to publish a textbook on a frequently changing domain topic have incentive to create such work.

Until that time, our textbook will remain self-published as it is now. Content creation and revision is performed using Microsoft Word. Content is safeguarded and version controlled using Vault, a source code control system available from SourceGear. Textbooks are currently available only in print format. But printing is performed on-demand via the university printing office, and students 
can pick up textbooks one business day after purchase, or have them delivered via United States Postal Service in seven to ten business days. As a final note: self-publication has allowed us to make the textbook available to students at approximately $60 \%$ savings over the traditionally published previous versions while retaining the same level of financial compensation.

\section{References}

CreateSpace: Self Publishing and Free Distribution for Books, CD, DVD. (n.d.). . Retrieved May 29, 2011, from https://www.createspace.com/

Creative Commons. (n.d.). . Retrieved May 22, 2011, from http://creativecommons.org/

Dog Ear - Self-Publishing Companies (n.d.). . Retrieved May 29, 2011, from

http://dogearpublishing.net/self-publishing-companies.aspx

Flat World Knowledge - Authors. (n.d.). . Retrieved May 27, 2011, from http://www.flatworldknowledge.com/authors

Flat World Students - Books. (n.d.). . Retrieved May 27, 2011, from http://students.flatworldknowledge.com/books

Hearing on: Are College Textbooks Priced Fairly (July 20, 2004). U.S. House of Representatives Committee on Education and the Workforce Subcommittee on $21^{\text {st }}$ Century Competitiveness. $108^{\text {th }}$ Congress, $2^{\text {nd }}$ Session.

Lulu Corporate Profile. (n.d.). . Retrieved May 24, 2011, from http://www.lulu.com/en/about/index.php

Lulu - How does the distribution process work?. (n.d.). Retrieved October 22, 2011, from http://connect.lulu.com/t5/ISBN-Distribution/How-does-the-distribution-process-work/ta-p/33620

MIT OpenCourseWare - About OCW (n.d.). . Retrieved May 19, 2011, from http://ocw.mit.edu/about/

OCW Consortium. (n.d.). . Retrieved April 18, 2011, from http://www.ocwconsortium.org/

OCW Consortium - Members. (n.d.). . Retrieved March 23, 2011, from http://www.ocwconsortium.org/members/members

Thompson, J. (2005). Books in the digital age: The Transformation of Academic and Higher Education Publishing in Britain and the United States (1st ed.). Cambridge, UK: Polity Press.

United States Government Accountability Office (July 2005). Report to Congressional Requesters: College Textbooks - Enhanced Offerings Appear to Drive Recent Price Increases. GAO-05-806.

\section{Biographies}

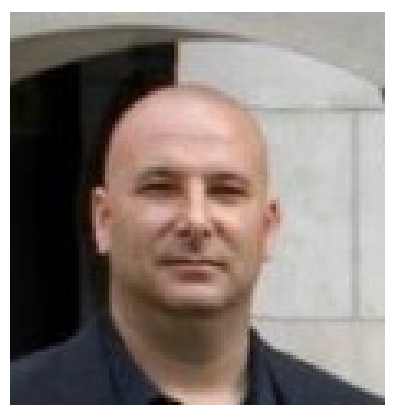

Ronald Erdei is a doctoral student in the College of Technology at Purdue University in West Lafayette, Indiana. He recently returned to the Department of Computer and Information Systems Technology to pursuing his Ph.D. full time. Focusing his career on data-centric systems, Ron has worked in the roles of application developer, database analyst, database architect, and database administrator. He is active in local user groups, and often speaks upon topics pertinent to data-tier application development. Ron's primary area of interest is information technology education, with particular emphasis upon optimizing content and delivery mechanisms for targeted populations. 


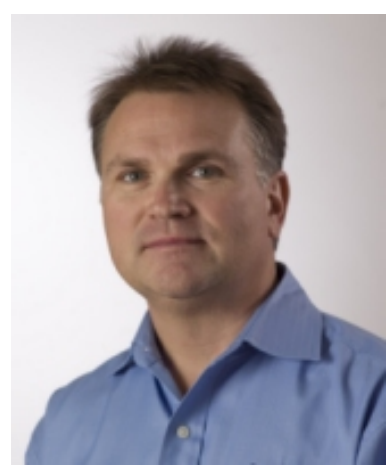

Kyle Lutes is an Associate Professor for the Department of Computer \& Information Technology (CIT) at Purdue University. Kyle joined the department in 1998 and is the chair of the department's software development curriculum. His teaching and scholarly interests cover a broad range of software development areas including software applications for mobile devices, data-centered application development, and software entrepreneurialism. He has authored/co-authored numerous papers and two college textbooks on various software developmentrelated topics. Prior to his current appointment at Purdue, Kyle worked for 16 years as a software engineer and developed systems for such industries as banking, telecommunications, publishing, healthcare, athletic recruiting, retail, and pharmaceutical sales. 